\title{
A Expressão Conceitual da Linguagem Jurídica.
}

\author{
Irineu Strenger \\ Professor Titular de Direito Internacional Privado na \\ Faculdade de Direito da Universidade de São Paulo.
}

O principal escopo deste trabalho pode ser resumido na seguinte proposição indagativa: A linguagem jurídica contém em si mesma a possibilidade de identificar a expressão conceitual do Direito?

Nossa tentativa será um esforço para desvendar alguns problemas internos do pensamento jurídico que se traduzem no processo da normatividade.

Partindo do pressuposto de que o direito e a lógica distinguem-se de outras ciências pelo fato de serem disciplinas normativas, pensamos que se pode estabelecer um paralelo explicativo a respeito dos modos do raciocínio jurídico e, a partir desta atitude, estabelecer uma discussão argumentativa.

Como bem enunciou KaLINOwSKY, todo termo não é evidentemente um termo jurídico, mas todo termo jurídico é uma expressão lingüística. Da mesma maneira, toda proposição não é uma regra jurídica, mas toda regra jurídica é uma proposição.

O aspecto que nos preocupa é exatamente a dissociação entre a linguagem do direito e o fenômeo lingüístico jurídico. Apesar de ambas serem expressões conceituais, nem sempre a comunicação se reduz numa norma analiticamente evidente, 
isto é, a validade ou invalidade das normas não é correlato deôntico do epistêmico verdade ou falsidade, porquanto uma norma pode ser válida ou não válida e um enunciado jamais pode ser ao mesmo tempo verdadeiro e falso.

Uma explicação apropriada de JuAn-Ramon Capella nos mostra que não é ilógico imaginar um sistema de normas como empiricamente possível, ainda que supondo a sua possibilidade como resultante de dados históricos, assim como é possível também que os homens cheguem a construí-lo. Nesta hipótese teríamos um sistema estranho à lógica e, portanto, insujeito a uma análise formal.

A reflexão jurídica visa a definir técnicas de raciocínio apropriadas e a limitar suas condições de aplicação.

Segundo nos diria Perelman o móvel das elaborações sistematizantes é imanente ao conjunto formado pelo pensamento e seu contexto, e não pelo pensamento isolado.

Nessa perspectiva global se compreende o caráter da discussão entre aqueles que entendem possível a referência ao real mediante descrição formalmente satisfatória sem, contudo desprezar a possibilidade do pensamento puro impor ao mundo suas exigências de racionalidade e os que não distinguem entre o plano ontológico da conduta e o plano lógico dos juízos.

Diríamos que o correlato teórico estaria na distinção de CARnap entre semântica pura e semântica descritiva, considerando a primeira como investigação empírica das características semânticas de linguagens historicamente dadas e a segunda, a análise dos sistemas de regras semânticas.

Tal colocação do problema nos levaria à concepção de que o direito moderno não pode escapar ao crivo analítico da lógica, sem perder-se de vista que o maior empenho da epistemologia jurídica se concentra na rigorosa determinação do 
objeto da jurisprudência, oscilando entre os extremos do direito como puro fato ou como pura norma ou pesquisa da efetividade das relações jurídicas, ou então, como análise da linguagem.

Na expressão de Miguel Reale a questão se coloca acima da pura objetividade lógica no sentido de que somente há uma interpretação de tipo histórico cultural inconfundível com a explicação histórico-filológica visto que, somente a primeira é capaz de compreender os modelos jurídicos na plenitude da sua significação objetiva, como experiência concreta.

A fenomenologia, entretanto, tem uma perspectiva a respeito da linguagem que encaminha a questão no sentido de demonstrar a existência de uma relação de tipo projetivo entre o sujeito e a situação concretamente vivida, isto é, fenomenologicamente a linguagem é um ato significativo que ultrapassa o simples material lingüístico.

Apontamos inicialmente um paralelismo estrutural entre lógica e direito com $o$ intuito de fundamentar a possibilidade de demonstrar que o material linguístico da ciência jurítica nem sempre é expressão conceitual da linguagem jurídica.

Em outras palavras, admitidas as funções da linguagem em termos de significação e compreensão, verifica-se que há uma dicotomia inevitável no processo interpretativo, porquanto a primeira função impõe uma atitude descritiva do real que tem como efeito impedir distorções entre o signo e o significado, isto é, constitui uma tentativa de reproduzir com a máxima fidelidade as estruturas objetivas do real.

A segunda função, ou seja a de caráter compreensivo, abrange a esfera histórico-cultural analisada por Miguel REALE e que desborda o plano histórico-filológico, porquanto esta se resolveria em termos semânticos enquanto que a primeira reflete uma relação necessária entre intencionalidade e situação. 
O problema conceitual da linguagem jurídica se impõe cada vez mais ao interesse do jurista que no futuro não poderá escapar aos efeitos inevitáveis do desenvolvimento da jus-cibernética, caracterizadora do preponderante papel da lógica jurídica de cujos métodos sairão as regras do raciocínio jurídico.

As relações jurídicas, põem entretanto, em confronto um grande número de parâmetros. E como diria Aurel DAvid, "não se pode tocar no cabelo de um homem vivendo em sociedade sem revolver todo o microcosmo desse indivíduo e, o macrocosmo social, até as suas províncias as mais longínquias. A lógica que deveria poder aplicar-se a esses imensos conjuntos e que se designou com o nome de lógica diálética parece encontrar nestas circunstâncias problemas contendo um número infinito de relações a um número de termos infinitos"

$\mathrm{O}$ aspecto mais importante e também mais complexo da apreciação conceitual da terminologia jurídica é, precisamente, vinculado ao fato de que a expressão conceitual da norma é um processo interpretativo e a ação de encontrar as consequiências mais ou menos evidentes, nem sempre coincide com o raciocínio da interpretação puramente lógica.

Em interessante análise Ziembinski lembra que os teóricos do direito na Polônia distinguem as regras puramente lingüísticas das regras teleológicas ou funcionais, mostrando que estas últimas são baseadas em certos pressupostos concernentes às avaliações atribuídas ao legislador, pessoa frequientemente ficta, cuja vontade estabelece uma semelhança com a vontade do próprio intérprete. $\mathrm{E}$ acentua que as regras funcionais e as regras lingüísticas entram, às vezes, em colisão obrigando a utilização de metaregras de interpretação.

$O$ essencial é que, em conclusão, se verifica que as regras de interpretação puramente lingüísticas podem ter uma significação considerável do ponto de vista do princípio da legalidade, mas, não são suficientes para constatar de maneira unívoca o sentido normativo do texto legal. 
Assim sendo, a pretensão de definir o jurídico pelo conteúdo material das normas leva a uma delimitação, "a priori", da competência das autoridades normatrizes.

Deixamos de lado a questão de saber se a relação entre forma e matéria deve ser pensada, porquanto admitimos que, no sentido kelseniano, a forma é entendida como função categorial constitutiva.

$\mathrm{Na}$ verdade, a aplicação do direito concebida como a comparação entre o conteúdo conceitual da norma, implicitamente da linguagem jurídica, e o conteúdo material real, pressupõe um processo estático, na base de elementos pressupostos, que está em oposição ao processo dinâmico, criador de conteúdo pelo próprio ato de decisão.

A distinção foi muito bem proposta por Miguel Reale ao apreciar a ciência do direito e a teoria da comunicação, mostrando que as funções desempenhadas pela linguagem do direito podem ser divididas em pragmáticas, referentes às relações existentes entre as expressões e os homens que as empregam; semânticas, as atinentes aos significados e às alterações dos significados das expressões, isto é, ao estudo de seu processo significativo e sintáticas, concernentes às relações ou à composição dos signos entre si, abstração feita de seus significados.

Pondera ainda Miguel Reale, interpretando KaliNowsKI, que dentre as funções pragmáticas as mais importantes são as de expressão e as de comunicação, esta última desempenhada pela linguagem da ciência do direito, enquanto que à primeira caberia papel mais relevante na linguagem do jurista, mas admite que a expressão não é senão um elemento da comunicação.

Com fundamento nessa distinção discernimos que a imposição volitiva do direito de onde decorre o possível conhecimento científico e a proposição lógico-jurídica há uma co- 
implicação suscetível de apoiar a elaboração de um sistema lógico-proposicional sem a exclusão da intenção axiológiconormativa.

A interpretação jurídica não pode ser concebida como fim de si mesma mas, um momento normativo e metodológicamente subordinado ao serviço da aplicação do direito, isto é, a interpretação jurídica ao concorrer na determinação do sentido juridícamente válido da decisão normativa atua metodologicamente para a aplicação concreta e nesta se consuma.

Pensamos ter ressaltado neste trabalho que a expressão conceitual da linguagem jurídica não obedece aos cânones interpretativos da linguagem não formal, fato que cria um sério obstáculo para os propósitos exegéticos segundo as modalidades tradicionais de interpretação e sugerem a impossibilidade de axiomatização da linguagem Iegal.

Essa realidade explica a tendência tecnificadora do direito e a utilização de expressões cada vez mais abstratas da linguagem legal que só pode ter por objeto as ações humanas, as quais não podem subsistir somente em função de um elemento teórico, mas, subsistem principalmente em função de um elemento ideológico, visto que, quando se recorre a um processo abstrativo, corre-se o risco de restabelecer o antigo formalismo jurídico.

For isso tem toda razão Miguel Reale ao afirmar, tratando dos modelos jurídicos, que a primeira distinção a fazer refere-se à intenção objetivada no ato da formulação do modelo jurídico, ponderando que todo modelo jurídico depende de uma tomada de posição perante os dados empíricos examinados, importando sempre um processo abstrativo e seletivo destinado a captar o sentido normativo dos fatos. Nestes termos considera os modelos teoréticos, que são, fundamentalmente, estruturas teóricas às quais cabe, de maneira primordial, a função interpretativa dos modelos prescritivos bem 
como dos processos de sua aplicação eficiente e justa, sem considerar, porém, o prescritivo como expressão de comandos vinculatórios da ação.

Os modelos prescritivos enunciados por Miguel Reale podem assumir diversos significados, como, por exemplo, o impositivo que vincula o destinatário a um único esquema de conduta; o interpretativo, que determina o significado obrigatoriamente atribuível a um dispositivo legal; o programático, que abre um leque de possibilidades de ação segundo um plano traçado de maneira genérica; o dispositivo, que prevê uma solução típica, aplicável na hipótese de ter sido prevista outra pelos interessados, ou ser inviável a via por eles escolhida.

De todas as ponderações acima formuladas chegamos à conclusão de que a expressão conceitual da linguagem jurídica tem seu fundamento na seguinte proposição: que o normativo jurídico implica, necessàriamente, uma intenção empírico-real, uma referência à realidade social-histórica e isto, não obstante, a necessária integração na intenção lógico-normativista de indispensáveis momentos de valoração.

Em conclusão; a dedução conceitual, seja por referência lógico-normativa seja por adequação material ao caso concreto - resultado é que a problemática da concreta aplicação do direito, da sua realização normativa, põe justamente a claro a impossibilidade de se persistir na idéia de que o direito vai por inteiro pressuposto ou que ele resulte num dado que bastaria interpretar para depois sem mais aplicá-lo, fato que ressalta a ambigüidade do termo interpretação se tivermos em conta as contradições entre o conceito da linguagem do direito e o conceito da linguagem do jurista. 